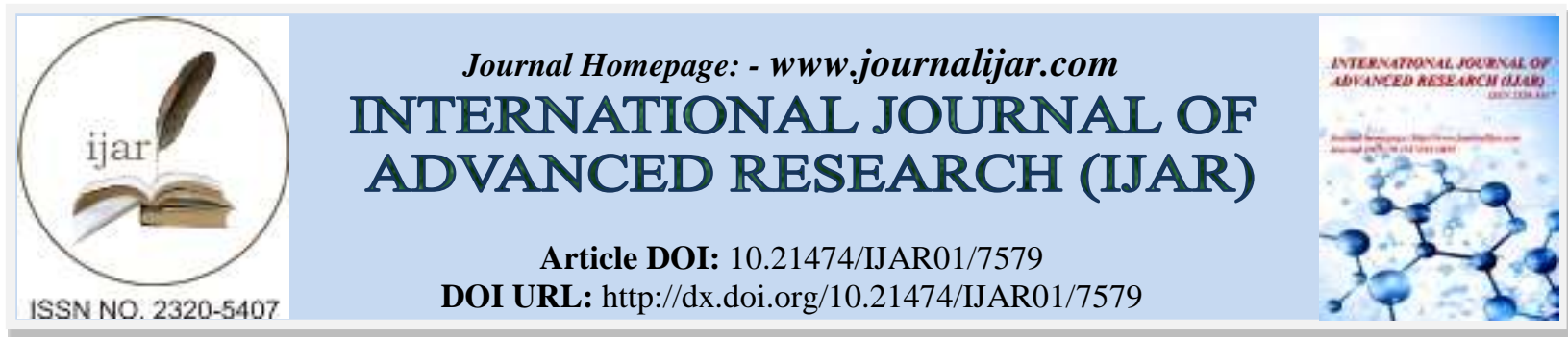

RESEARCH ARTICLE

\title{
TO FIND OUT PREVALENCE OF MUSCULOSKELETAL PAIN BY CARRYING HEAVY HANDBAGS AMONG COLLEGE GIRLS AND ITS RELATION WITH THEIR BMI.
}

Indu Priya Gunnam(MPT), Prof. Ahmed Thajudeen and Prof. Murali Sivanandam.

The Oxford College of Physiotherapy, Bangalore, Rajiv Gandhi University of Health Sciences, Karnataka.

\section{Manuscript Info}

Manuscript History

Received: 16 June 2018

Final Accepted: 18 July 2018

Published: August 2018

Keywords:-

Handbag, handbag optimal weight, handbag carriage, musculoskeletal pain in students.

\section{Abstract}

Background: Students aged 18-30yrs undergo rapid musculoskeletal development and an application of external forces (handbags) cause musculoskeletal disorders. Musculoskeletal pain is one of the most important pains among students.

Objectives: This study was carried out to investigate the prevalence of musculoskeletal discomforts and pain in various regions of the body due to heavy handbag usage in university/college students and to examine its association with the type of handbag, handbag load, time spent carrying load, distance travelled carrying load, and the student's body mass index(BMI).

Methods: This co-relational descriptive study was conducted on students selected from different colleges of Oxford educational institutions. The study goals were explained and obtained informed consent. Their Bag weight, Body weight and Height was measured. The data on handbag use were collected using a self administered questionnaire and the data on musculoskeletal pains was taken using Orebro musculoskeletal pain questionnaire. Statistical analysis was conducted using Microsoft excel.

Results: The results shows that $83.3 \%$ reported musculoskeletal pain/discomforts. The overall prevalence of discomforts/pain in Neck $25 \%$, Shoulder $21 \%$, Lower back $23 \%$, Upper back $19 \%$, Leg $8 \%$, Arm $4 \%$. The average handbag weight carried was $3.2 \mathrm{~kg}(3.29 \pm 1.12,35 \%)$. The results shows that Bag weight is correlated with the BMI $(\mathrm{p}<0.05)$, Carrying duration $(p<0.05) \&$ Pain $(p<0.05)$ which states that the results are statistically

significant. But no correlation found between bag weight \& distance travelled daily with the bag on the shoulders and as ( $p>0.05)$.

Conclusion: Musculoskeletal pain/discomforts is reported among students of different colleges with an overall prevalence of $(83.3 \%)$. This discomfort/pain is potentially influenced by bag weight, carrying duration \& BMI. This study proves that there is correlation between the above variables.

Copy Right, IJAR, 2018,. All rights reserved.

\section{Corresponding Author:- Indu Priya Gunnam.}

Address:- The Oxford College of Physiotherapy, Bangalore, Rajiv Gandhi University of Health Sciences, Karnataka. 


\section{Introduction:-}

In modern society fashion is changing and westernization is spreading more and more. Not only working women, but also college students and school children are being addicted to this handbag fashion, especially in metro cities. Loading all the things in it and carrying it on only one side for the purpose of style or good looking. Carrying heavy handbags causes malalignment of the spine as they either lower or raises the shoulder on which the bag is slung across. This again leads to permanent changes in the posture, soon enough leading to multiple musculoskeletal pain/discomfort. ${ }^{(1)}$

The musculoskeletal problem starts when it is loaded up with wallet, laptop, and pair of footwear, cell phone, tablet, iPod, pen drive, power bank, charger, lunch box, water bottle, book or magazine, maybe both, along with a makeup kit and a few work files and carrying the thing everywhere. Soon a nagging ache starts that spread through the neck, across the top of the shoulder blade, and over to the arm. ${ }^{(2)}$

It pulls on a web of nerves that can cause aching or shooting pain from the neck down the arm. In addition, every time carrying the heavy loaded bag over the shoulder, the upper back muscles that stabilize the shoulder blade must struggle to counterbalance that weight; eventually they get overworked. Loading 10 extra pounds onto one side of the body causes the trunk to tilt sideways to compensate, adding lower-back pain. ${ }^{(2)}$

Unilateral loading modes produce which results in significant greater postural deviations and adaptations. The effect of carrying the load on the shoulder significantly increases the thoracic lateral curvature in the frontal plane and decreased the thoracic kyphosis in the sagittal plane. ${ }^{(3)}$

Over at core concepts, increasing cases of shoulder and neck pains were noted due to heavy handbags usage also known as Handbag syndrome ${ }^{(4)}$ A heavy handbag, shoulder bag, or purse can injure the neck, back and shoulders. The neck has a natural curve that evenly distributes forces on the spine. Hence, when a person carries a heavy bag on one side over a long period of time, this natural curve starts to get distorted which can lead to chronic neck and shoulder pains, back pain, and even headaches. Left untreated, can lead to more serious injuries such as herniated discs and accelerated degeneration of the cervical spine. ${ }^{(4,5)}$

BMI does not measure body fat directly, but research has shown that BMI is moderately correlated with more direct measures of body fat obtained from skin fold thickness measurements. In general, BMI is an inexpensive and easyto-perform method of screening for weight category, for example underweight, normal or healthy weight, overweight, and obesity. BMI appears to be as strongly correlated with various metabolic and disease outcome as are these more direct measures of body fat. Formula: weight $(\mathrm{kg}) /\left[\text { height }(\mathrm{m})^{2}\right]^{(6)}$

Carrying a fully or above average loaded bag on a daily basis can cause stress and injury to the body. Females don't realize that it's their bag causing the discomfort. It is thought that, it is the wrong sitting posture at the computer, or the lifting techniques, when it might be the repetitive action of carrying their bag every day. Supported by a study, handbags are weighed, which causes repetitive strain injury and pain in the shoulder and neck ${ }^{(7)}$

The link between load carriage and musculoskeletal pain in the neck, back and shoulders has been well documented with prevalence of back pain documented to be as high as 30-51\% in students and requiring 4-31\% to seek medical intervention. The actual mode of load carriage has been shown to cause different postural shifts resulting in adverse stress and strains on the surrounding spinal structures resulting in back pain ${ }^{(8)}$

Today, students low mobility along with their taking on stressful situations caused by industrial life has increasingly led to psychological and physical complications, such as musculoskeletal disorders in this age group Carrying bag is a means of applying external forces to the body and has been commonly associated with postural and gait deviations. Heavy bag load and improper bag use can be threatening to the health of students as studies have shown these factors are associated with muscle imbalance, repetitive strains to the body, intense pressure on joints and ligaments, increase in energy consumption and decrease in lung volumes ${ }^{(9)}$. In recent years, there has been increase in the incidence of musculoskeletal complaints due backpack use among college students ${ }^{\text {(10) }}$. The associated longterm discomforts or pain may lead to potential chronic pain origin injury resulting in student's absenteeism from lessons and low productivity thereby affecting students' wellbeing and future careers ${ }^{(11)}$. 
The recommended guidelines for bags load vary among organizations. The American Occupational Therapy Association has recommended backpack load limit not more than $10 \%$ of student's body weight ${ }^{(12)}$ while American Academy of Pediatrics recommended safety limit ranging 10 to $20 \%$ of the student's body weight ${ }^{(13)}$ However, it was suggested that these recommendations are feasible with practical goal and it is better to be limited at $10 \%$ or less $^{(14)}$ It is equally important that students develop an awareness of these issues in order to monitor their own $\operatorname{practices}^{(15)}$.

Factors such as backpack design, duration and frequency of carriage, inadequate distribution of weight in the backpack, method of transport to school, manner in which the weight is carried as well as improper carriage may all affect the demands on the musculoskeletal system leading to occurrence of musculoskeletal symptoms ${ }^{(16)}$.

Carrying of a shoulder bag for prolonged periods of time can have negative effects on human body. These effects include musculoskeletal misalignment, muscle spasms, and postural asymmetry. Repetitive periods of postural asymmetry can lead to asymmetric muscular activity which may contribute to the development of back pain over time. Despite the warnings about harmful musculoskeletal effects of carrying shoulder bags, students continue to use shoulder bags because of convenience and the need to get needed items to class while moving freely throughout the $\operatorname{day}^{(17)}$.

According to the literature of a study, there are a number of students of all ages who prefer to carry one strap shoulder bags, and the majority of reports indicate that loads carried by students are greater than the recommended limits ${ }^{(18)}$. Carrying a shoulder bag throughout the duration of high school and college years has been shown to lead to back pain. The American Physical Therapy Association (APTA) suggests that "Backpacks weigh no more than $15 \%$ of the carrier's total body weight" (19).

Several studies also concur that an acceptable range of weight for bag carriage is between $10 \%-15 \%$ of the individual's body weight. Another Factor that may aggravate or cause musculoskeletal problems resulting from shoulder bags is uneven weight distribution throughout the lower extremities. They found that disproportionate forces placed through the lumbar spine while carrying a shoulder bag are transferred disproportionately to the lower extremities. Carrying a unilateral strap shoulder bag may contribute to postural asymmetry and result in more weight bearing distributed through one lower extremity versus the other ${ }^{(20,21)}$.

Researchers from the University of California, San Diego stated that limitations in shoulder bag weights may reduce the number of national emergency room admissions per year approximately 7,500 related to shoulder bag injuries. This illustrates the importance that proper shoulder bag use be emphasized during the years of the highest growth rate, as it can be inference that the susceptibility for injuries and permanent postural abnormalities are more likely to occur during this period. Secondary ossification of the vertebrae is not complete until the mid twenties. Therefore the spine may also be susceptible to injury throughout the college and post graduate years ${ }^{(22)}$.

\section{Need Of Study :-}

There is the paucity of information regarding the musculoskeletal problems in students caused due to their loaded bags. Most of the studies were done on students using loaded backpacks leading to the musculoskeletal pain, but none studies done on handbags leading to musculoskeletal pain due to lack of awareness that handbags can lead to pain \& postural problems. Hence, there arise a need and background for the genesis of this study to help the students to know the effects of loading on daily basis.

\section{Aim \& Objectives:-}

The purpose of this study was to :

(a) Investigate the prevalence of musculoskeletal pains due to heavy handbag use among college girls in Oxford educational institutions, Bangalore

(b) Investigate the relationship between

- BMI

- Handbag weight

- Frequency of carriage

- Duration of carriage

- Musculoskeletal pain 


\section{Reviews Of Literature:-}

Bettany Saltikov et al (2008) ${ }^{(3)}$ :- Study was done to investigate the effects of carrying a rucksack on each shoulder or on both on $3 \mathrm{~d}$ spinal curvature in healthy young students. A convenience of sample of 30 healthy young adults participated in this study. Procedure was a Microscribe $3 \mathrm{dx}$ digitizer recorded the three dimensional coordinates of 13 key anatomical landmarks along the spine in four different loading conditions. No rucksack, carrying a rucksack with $17 \%$ body weight simultaneously on both shoulders and solely on the right or left shoulder. Results were carrying load on both shoulders resulted in no difference in frontal plane angle but significantly decreased the thoracic kyphosis in the saggital plane. Carrying the load on one shoulder significantly increased the thoracic lateral curvature in the frontal plane and decreased the thoracic kyphosis in the saggital plane. This study confirms that carrying a $17 \%$ load causes significant changes in spinal alignment. This study is in relation with the current study as they have described, about postural changes due to unilateral loading \& current study also involves unilateral loading leading to the msk pain.

Clare Haselgrove et al $(2008)^{(16)}$ :- Study was done to find out the use and perceived load of school bags and the prevalence of spinal pain different between male and female students. Procedure was it was a cross sectional observational study done on 1202 students recruited from the raine cohort study. Use and perceived load of bags and spinal pain were measured by questionnaire. Results were prevalence of neck and back pain was approximately $50 \% .53 \%$ of females reported neck pain compared with $44 \%$ of males. Almost half of participants carried their bag for more than 30 minutes per day with $85 \%$ carrying their bag over both shoulders. Bags were felt to be heavy by $54 \%$ and to cause fatigue by $51 \%$. The current study relates in context of this study in finding out prevalence of musculoskeletal pains due to load of bags.

Motmans RR et al (2006) ${ }^{(17)}$ :- Study was done to observe the trunk muscle activity in different modes of carrying bags. Procedure was Electromyography activity from rectus abdominis and erector spinae was recorded bilaterally in five static conditions: no bag, shoulder bag, backpack, front pack, double pack. 19 students carried a load of $15 \%$ of their body weight. Results were a double pack, with the load equally distributed in a front and a backpack, showed no significant differences in EMG activity compared with unloaded standing. The activity levels of erector spinae significantly decreased while carrying a backpack and increased with a shoulder bag and a front pack. Rectus abdominis revealed significantly higher EMG levels in the backpack trial. Asymmetrical activity between the right and the left part of the back muscles was clearly observed while carrying a shoulder bag with the weight at the right side of the body. The abdominal muscles revealed a slightly significant asymmetry for the shoulder bag and also for the backpack. The more the load on one side of the body, more the pain $\&$ more the changes in the muscle activity and Hence there is a relation between the current study \& this study.

Bettany Saltikov et al (2012) ${ }^{(23)}$ :- Study was done to evaluate the effect of carrying three different types of bag. Shoulder, Front and Handheld, each containing a load of $15 \%$ body weight. Procedure was the study involved 25 university students. A repeated measures design was used to record the effects of four conditions using No load, a front pack, a shoulder bag, and a handheld bag. Measurements with ISIS 2 were taken 5 minutes post loading. All of the conditions were randomized in an attempt to offset any order effects. Results showed an increase in extension and lumbar lordosis angles for the front bag, an increase in flexion and reduced lumbar lordosis in the shoulder and hand held bags, kyphosis curves were also significantly increased in the hand held bag, right unilateral load carriage also demonstrated the greatest right volumetric asymmetry. As there is greatest asymmetry in the posture due to unilateral loading, so will be greater pain in the subjects. And such there is a relation between this study \& current study.

Oshea et al (2006) ${ }^{(24)}$ :- Study was done to examine the changes in back shape that occurred in response to asymmetrical load carriage of handbags, either in one shoulder (same side) or across the body (cross body), in healthy young adults. Procedure was a convenience sample of 21 physiotherapy students randomly performed three trails (unloaded, same side loaded, cross body loaded) in standing with a $15 \%$ body load. The Microscribe $3 \mathrm{dx}$ digitizer recorded the three dimensional coordinates of 15 key anatomical landmarks on the back in the three conditions. Results were there is significantly less impact on spinal posture from cross body loading as compared to same sided loading. In accordance with this study, current study also, is to prove that there are greater musculoskeletal changes due to unilateral loading.

Firouz Amani et al (2018) ${ }^{(25)}$ :- Study was done to determine the prevalence of Musculoskeletal disorders and its related complications among students in Ardebil. Procedure was, it was a cross sectional descriptive study done on 
158 students selected by random sampling using Nordic musculoskeletal pain questionnaire. Results were of all the students 55\% had pains in musculoskeletal system. The most severe pain was reported in knee zone and mildest pain in pelvic zone. Overall knee pain was revealed in $29.5 \%$ and neck pain in $27.3 \%$. There was a significant relationship between body mass index (BMI) of students and musculoskeletal pain. Additionally, a significant relationship between height and musculoskeletal features was seen. There is also a significant relationship between the type of school bag and musculoskeletal disorders. In context of this study, the current study also is to prove/ to find out the correlation between musculoskeletal pain \& BMI of the subjects.

Yasmin Qureshi et al (2012) ${ }^{(26)}$ :- Study was done to investigate whether there is a way to wear a unilateral strap shoulder bag that will allow more symmetrical posture alignment, preventing potentially harmful musculoskeletal effects. Procedure was 65 college students; each participant donned a unilateral strap shoulder bag two different ways on the dominant and the non dominant shoulder while standing on the postural scale analyzer to measure lower extremity weight distribution. Results were a significant improvement in lower extremity weight distribution was found in right hand dominant subjects when wearing a shoulder bag draped across the left shoulder to right hip. When individuals who are right hand dominant wear a shoulder bag draped across the left shoulder, the weight distribution through the person's lower extremities becomes more equal indicating improved postural symmetry in static standing. Current study is in context with this study as it involves the unilateral loading \& the changes in musculoskeletal system of the body.

Mackie HW et al (2005) ${ }^{(27)}$ :- Study was done to determine the effects of different load carriage configurations on shoulder strap tension forces and shoulder interface pressure during simulated student's load carriage. Procedure was a load carriage simulator was used to compare shoulder strap forces and shoulder pressure for 32 combinations of gait speed, backpack weight, load distribution, shoulder strap length and use of hip belt. The results showed that the manipulation of backpack weight, hip belt use and shoulder strap length had a strong effect on shoulder strap tension and shoulder pressure. Backpack weight had the greatest influence on shoulder strap tension and shoulder pressure, whereas hip-belt use and then shoulder strap adjustment had the next greatest effects respectively. The current study is in relation with this study as it talks about the pressure of using the strap bags \& load of bags on the body \& the changes according to them.

Yuing Hu et al (2008) ${ }^{(28)}$ :- Study was done to investigate the prevalence of self reported musculoskeletal discomfort and pain in university students and to examine its association with the type of backpack, backpack load; time spent carrying loads and the student's BMI. Results were a high prevalence $85 \%$ of the university students self reported musculoskeletal pain and discomfort and $84 \%$ of the participants reported knowledge of the potential consequences of incorrect backpack usage. An emerging trend between musculoskeletal symptoms and time spent carrying backpacks mean $=2.3 \mathrm{hr}$ for subjects with pain, $3.4 \mathrm{hr}$ for subjects with discomfort. This study is in accordance with the current study as the context is about prevalence of musculoskeletal pains \& its correlation with the BMI of subjects.

Rebecca Hardie et al $(2015)^{(29)}$ :- Study was done to investigate the effects of different bag conditions on muscle activity of the Trapezius, Erector spinae and Latissimus dorsi muscles in female university students during walking. Procedure was twelve female university students walked on a treadmill for 5 minutes at $1.1 \mathrm{~m} / \mathrm{s}$ during five conditions; control, 1 strapped rucksack, 2 strapped rucksack, ipsilateral shoulder strap and contralateral shoulder strap, each containing $10 \%$ bodyweight. Electromyography for the Trapezius, erector spinae and latissimus dorsi was recorded for the last 30s of each condition. Two-way ANOVA and paired t-tests were used to identify differences between right and left muscles and between bag conditions. Results showed that muscle activity of the left Trapezius was significantly higher than the right Trapezius during the 1 strap rucksack condition. For the left Trapezius, the 2 strapped rucksack and the control condition had significantly lower muscle activity compared to the 1 strapped rucksack and the ipsilateral shoulder strap. For the left erector spinae muscle, there was significantly greater muscle activity when wearing the contralateral shoulder strap compared to the control. For the right erector spinae, significantly lower muscle activity was observed when wearing the 2 strapped rucksack compared to the ipsilateral shoulder strap and contralateral shoulder strap. There were no significant differences in muscle activity of the latissimus dorsi muscles between any of the bag conditions. These findings suggest that a two strapped rucksack should be used when carrying loads to reduce spinal muscle activity which may in turn reduce reports of back pain in female students. This study is in accordance with the current study as its context involves about the unilateral strap bag loading \& the changes in the musculoskeletal system. 
Aminu. A. Ibrahim et al (2015) $)^{(30)}$ :- Study was done to investigate the prevalence of musculoskeletal discomforts in various regions of the body due to bag use and to examine its association with certain perceived correlates. Procedure was this was a cross-sectional analytic study conducted among 500 participants of SRM University in Chennai, India. Data on bag use were collected using a self-administered questionnaire and discomforts using the Nordic musculoskeletal questionnaire. Results were a high percentage of respondents about $82.2 \%$ reported discomforts. Prevalence of discomforts in neck were $48.6 \%$, shoulder $61.2 \%$, elbow 11.8\%, wrist/hand 14.2\%, upper back $38.2 \%$, lower back $29 \%$, hips/thigh 19\%, knee $17.2 \%$, and ankle $16.6 \%$. The average bag weight carried was $3.7 \mathrm{~kg}$ about $6.5 \%$ respectively. Gender was associated with shoulder, elbow and hip/thigh discomforts with females being more likely to suffer discomforts than males. Body mass index (BMI) was associated with occurrence of knee and ankle/feet discomforts. Relative bag weight was associated with shoulder and low back discomforts. While frequency of schoolbag carriage was associated with ankle or feet discomforts. There was no association between manner of bag carriage, duration of bag carriage and discomforts. Majority of the respondents $72.1 \%$ perceived their bag weight as being normal and also $75.2 \%$ aware of the potential consequences of incorrect carriage of bag. This study is in context of the current study, so as taken as reference.

Phonpichit et al (2016) ${ }^{(31)}$ :- Study was done to investigate the optimal weight for carrying a handbag in different ways. Procedure was this study involved 13 healthy females randomized into four carrying patterns such as no load, bag weight of $5 \%$ body weight, $7 \%$ body weight, $10 \%$ body weight, who were walking barefoot on the platform at a preferable speed. The centre of pressure was collected by the platform. In observation, the centre of pressure was towards the carrying side when carrying a greater load. Results were asymmetrical activities of the upper trapezius and erector spinae were shown. The discomfort areas were the right upper trapezius and right finger flexor muscles. Conclusion was continuously carrying a handbag greater than $10 \%$ body weight can cause musculoskeletal problems. The study is in context with the current study, about handbag load \& changes in the musculoskeletal system, so as taken as reference.

Farshad Arghavani et al (2014) $)^{(32)}$ :- Study was done to identify the risk factors associated with musculoskeletal disorders by comparing the prevalence of musculoskeletal pains among the students while carrying heavy bags. Procedure was 800 students marked their painful areas on body maps. Results were $54.1 \%$ female, $45.9 \%$ male. $48.9 \%$ weight on both shoulders. $40.4 \%$ on their right shoulder. $10.6 \%$ on their left shoulder. $68.02 \%$ often had pain on their right. While $31.98 \%$ had pain on their left side. $10.8 \%$ never felt pain, $42.3 \%$ rarely felt pain, $32.3 \%$ mostly and $14.5 \%$ always had pain. This study proves that there was greater pain on unilateral loading, so the current study is in context with this study.

Rina Koshi et al (2014) ${ }^{(33)}$ :- Study was to investigate the prevalence of neck, shoulder and back pain in students using bags. A co-relational research was conducted in Mangalore which included 580 students. Procedure was their bag weight, body weight and height were measured and the subjects having pain either in the neck, shoulder or back were given McGill Melzack pain questionnaire to be filled. Results were, Descriptive analysis revealed that the percentage of bag weight on body weight ratio is more in females compared to males. $6.03 \%$ of subjects carried bag weight weighing more than $15 \%$, out of which $8.57 \%$ subjects complained of pain either in the neck, shoulder or back. The correlation between bag weight and pain was analyzed using Karl Pearson's correlation which is perfect positive. Analysis of correlation between BMI with percentage of bag weight in males is more compared to females. The prevalence of students having pain was $2.93 \%$ due to bags. This study is similar in context of the current study, so taken as reference.

Linton et al(2003) $)^{(34)}$ :- Study was done to test the predictive utility of Orebro Musculoskeletal Pain Questionnaire(OMPQ) in identifying patient at risk for developing persistent musculoskeletal pains/problems. Procedure was, 107 participants were taken from primary care units and were given questionnaire to complete. Their cases were followed for 6 months to assess outcome with regard to pain, Function and Absenteeism due to sickness. Results shows that $68 \%$ classified into one of the 3 groups, $81 \%$ classified under category of pain, whereas $71 \%$ classified into other two groups. From total score, cutoff score of 90 points had a sensitivity of $89 \%$ \& specificity of $65 \%$ for absenteeism due to sickness. Whereas sensitivity of $74 \%$, specificity of $79 \%$ for functional ability. In Conclusion the results are indicating that OMPQ is a clinically reliable \& valid instrument. The total score was a good predictor of future absenteeism due to sickness as well as function \& pain. This screening instrument is found to have satisfactory test-retest reliability $(0.83) \&$ validity in a study of 142 patients. Using a cutoff score of 105 , the specificity was found to be (0.75) \& sensitivity (0.88). A cutoff score of 112 correctly identified $80 \%$ of patients 
failing to return to work. This study helps in the current study's outcome result \& its significance, so taken as reference.

Westman et al(2008) ${ }^{(35)}$ :- Study was done to validate the OMPQ for patients with Non Acute pain problems(e.g. : 1-6mnths sick leave) \& compare to other relevant questionnaires. And also for the early identification \& intervention with those that run the risk of developing long term disability associated with long term work absenteeism. Method was, 158 patients with musculoskeletal pain \& disability recruited to a multidisciplinary rehab project and at $3 y r s$ follow up visits. Results obtained as, the OMPQ predicted future sick leave, health \& was found to have six factors. Conclusion was, the OMPQ was a good predictor of outcome and has been used \& validated in several studies for participants with mainly non acute problems. This study is helpful for the current study in outcome result $\&$ its significance, so taken as reference.

\section{Methodology:-}

Study design:

Observational Co relative study

\section{Study duration:}

1 year

\section{Source of data :}

Oxford Educational Institutions, Bangalore.

- College of Business Administration

- College of Arts

- College of Sciences

- College of Law

- College of Pharmacy

- College of Nursing

- College of Physiotherapy

- College of Engineering

- College of Dental

\section{Population :}

Students of Oxford colleges using handbags with/without musculoskeletal pain due to Bag load.

\section{Selection criteria :}

Inclusion criteria :

- 18-30yrs

- Cooperative

- Using the Handbags

- All types of Built(Ectomorphic, Endomorphic, Mesomorphic)

-

Exclusion criteria :

- Any Recent Shoulder and Neck Injuries

- Pain history of Non mechanical origin

- Any Recent or Previous History of Fractures

- Shoulder Impingement Syndromes

Sampling method \& Sample size :

Sampling method : Convenient sampling

Sample size : 100

Material required : Pen, Questionnaire, Data collection sheet, Luggage weighing meter, Body Weighing scale, Height measuring tape/scale, BMI calculator.

Procedure : 
Potential respondents were registered students of Oxford Educational Institutions and were approached in their lecture theatres or classes after a prior informed consent was obtained from the college authorities and ethical approval obtained from the research ethical committee of oxford educational institutions. Informed consent was obtained from the participants after explaining the procedure and benefits of the study to avoid any bias. They were ensured that confidentiality of the data would be maintained.

The handbag weight, body weight and height of the participants were then collected. A standard scale was used to measure the handbags (Digital luggage weighing scale), body weight is measured through Digital weighing scale and height through Inch tape. Using this data, BMI was computed in $\mathrm{kg} / \mathrm{m}^{2}$ and the relative handbag weight was estimated as a percentage of the student body weight. 2 Questionnaires were administered on the respondents in this study.

The $1^{\text {st }}$ questionnaire was created by researcher which consists of the

$>$ Demographic details of the students : Age, Gender, Weight, Height and Bag weight

$>$ Close ended questions :

- Manner of carriage (on shoulder or hand carry method)

- Frequency of carriage (twice or multiple)

- Duration of carriage daily basis (<10mins, $10-20,20-30,30-40,40-50,50-60,>60 \mathrm{mins})$

- Duration of travel daily along with the bag on shoulders (how many minutes or hours)

- Mode of travel daily (car/bus/bike/walk/auto).

The $2^{\text {nd }}$ questionnaire was developed by Linton \& Boersma. The questionnaire is the most popular survey tool for detecting Musculoskeletal disorders(MSDs) \& was previously used previously in related studies. Data on MSDs was collected using this prevalidated questionnaire OMPQ(Orebro Musculoskeletal Pain Questionnaire). It predicts longterm disability and failure to return to work when completed 4 to 12 weeks following a soft tissue injury. A cut-off score of 105 has been found to predict those who will recover with $95 \%$ accuracy, those who will have no further sick leave in the next 6 months with $81 \%$ accuracy, those who will have long-term sick leave with $67 \%$ accuracy \& A cut-off score of 130 correctly predicted $86 \%$ of those who failed to return to work.

The respondents were asked to answer the questionnaire appropriately if they had experienced any pain or discomfort in the last 1 month to $1 \mathrm{yr}$ in different parts of the body such as neck, shoulder, upper limbs, upper \& lower back, and lower limbs due to heavy bag usage. The questionnaire was explained keeping in mind other factors that can lead to MSDs. The purpose of the questionnaire and how it should be answered was explained.

The questionnaire was pretested using a convenience sample of 10 students from the Faculty of Physiotherapy to improve comprehensibility and clarity of the questions and instructions. In addition potential problems with item interpretation were identified and resolved. The questionnaires were distributed and collected at the spot after filling up.

The data thus obtained was then subjected to statistical analysis using MS Excel in order to determine the prevalence of musculoskeletal pain in college going students due to the weight of handbags and to find out the relation between BMI and percentage of bag weight of subjects with pain. For analysis, results were presented as Mean, Range, Standard Deviation for Quantitative variables and were summarized by absolute Frequencies and Percentages for Categorical variables. $P$ values of 0.05 or less were considered statistically significant.

\section{Results \& Statistical Analysis:-}

Out of 120 students participated in the study, 100 students had musculoskeletal pains. The statistical results of the baseline characteristics of participants are shown in the table below, where $\mathrm{N}$ represents the no. of samples.

Table 1 :-Baseline characteristics of the subjects

\begin{tabular}{|c|r|r|r|r|r|}
\hline & $\mathrm{N}$ & Min Range & Max Range & Mean & $\begin{array}{c}\text { Standard } \\
\text { Deviation }\end{array}$ \\
\hline Age & & & & & \\
\hline Bag Weight $(\mathrm{Kg})$ & 100 & 18.0 & 27.0 & 20.800 & 2.5937 \\
\hline
\end{tabular}




\begin{tabular}{|l|r|r|r|r|r|}
\hline Carrying Duration(Months) & 100 & 1.0 & 72.0 & 14.150 & 13.7241 \\
\hline Travelling Distance(Minutes) & 100 & 5.0 & 180.0 & 36.050 & 35.3717 \\
\hline Body Weight(kg) & 100 & 34.9 & 85.7 & 54.460 & 9.3510 \\
\hline Body Weight(cm) & 100 & 140.5 & 173.0 & 158.544 & 6.5023 \\
\hline BMI & 100 & 14.3 & 33.6 & 21.708 & 3.6796 \\
\hline Questionnaire Score & 100 & 19.0 & 164.0 & 89.220 & 24.7731 \\
\hline Valid N (list wise) & 100 & & & & \\
\hline
\end{tabular}

BMI was calculated by percentages to find out the prevalence in the students in which underweight $<18$ were $(14 \%)$, normal weight $18-24(69 \%)$, overweight $25-29(13 \%)$, obese $>30(4 \%)$. The results were shown through the graph given below.

Graph 1 :-BMI Categories \& Percentages of Subjects

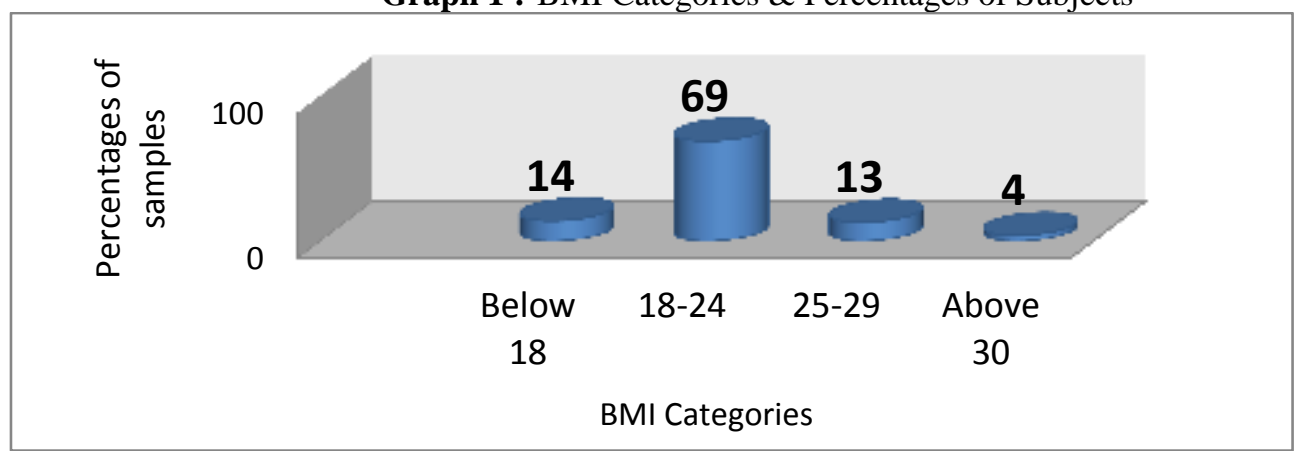

According to the obtained results, overall prevalence of pain in the musculoskeletal system in last 1 month was $83.3 \%$ and others did not report any similar pain due to bag. The most severe pain is reported in the $\operatorname{Neck}(25 \%)$ followed by Low back pain(23\%), Shoulder pain(21\%) \& Upper back pain(19\%), whereas least pain reported in the Leg pain(8\%) \& Arm pain(4\%) respectively. These results are statistically shown through Percentages to find out the prevalence in the students in the chart/graph below.

Graph 2 :-Pain Regions \& Percentages of samples

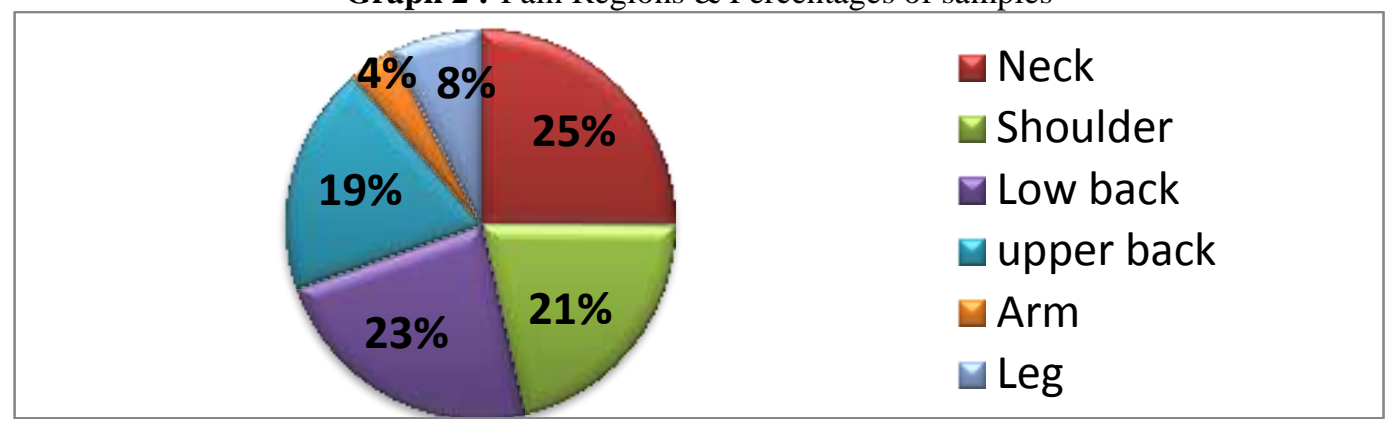

The girls $34 \%$ carried their handbag with overall average weight of $3 \mathrm{~kg}(3.29 \pm 1.12)$. The remaining bag weight and the percentage of samples carrying the loads were represented through the graph/chart mentioned below.

Graph 3:-Bag weight \& Percentages of samples

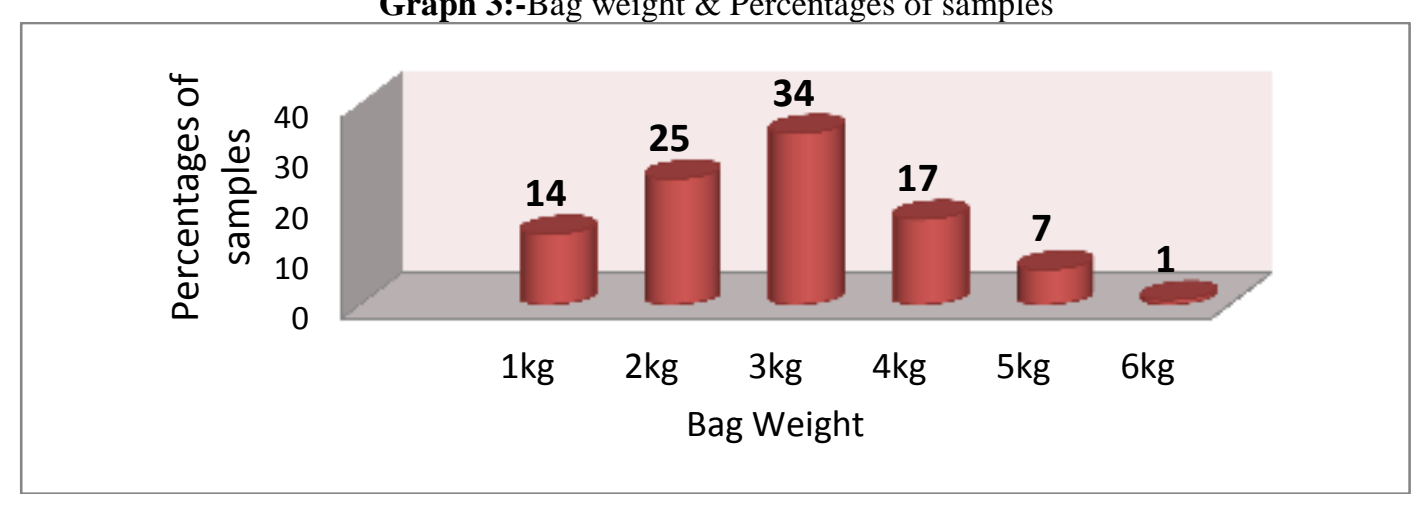


They carried most frequently during the day. About $16 \%$ carried their bag for $<10$ mins, $33 \%$ for $10-20$ mins, $13 \%$ for $20-30 \mathrm{mins}, 1 \%$ for $30-40 \mathrm{mins}, 7 \%$ for $40-50 \mathrm{mins}, 23 \%$ for $50-60 \mathrm{mins}, 7 \%$ for $>60$ mins every day.

Graph 4:-Percentages of subjects \& their Travel Duration(Mins)with bag carrying daily.



Graph 5 :-Percentages of samples \& Bag load Carrying duration(Months)

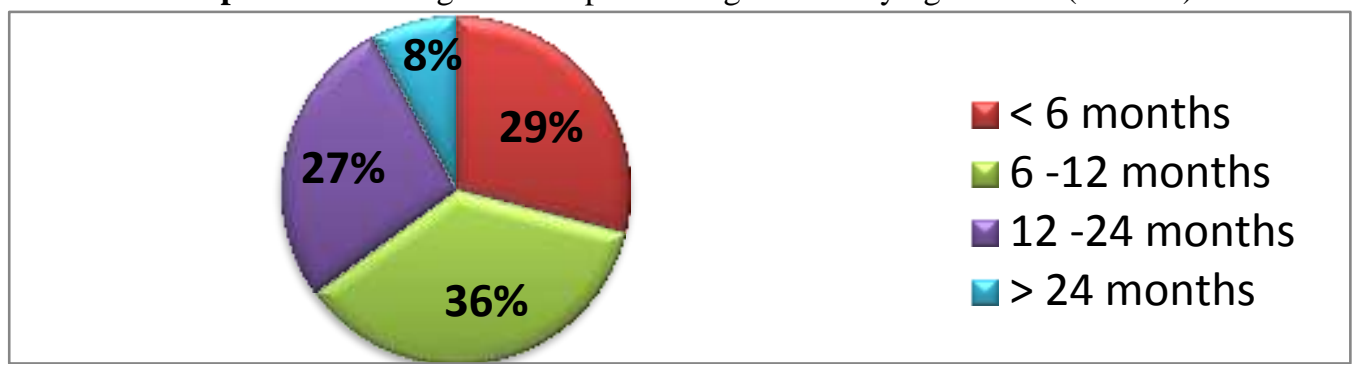

The questionnaire had a response of $100 \%$ \& the cutoff score has been divided statistically into 4 categories to find out the prevalence with other variables as Minimal pain <75, Moderate pain 75-105, Moderate to Severe pain 105130, Severe pain $>130$. It was observed that most of the respondents carried their college bag/handbag weighing less than $10 \%$ of their bodyweight \& still suffering with the musculoskeletal pains/discomforts. Studies shows frequent carriage of handbags on one shoulder is mostly associated with low back symptoms. This could be attributed to the fact that unilateral loading causes more postural deviation than bilateral loading on shoulders. Students who carried their college bag/handbag several times during the day were more likely to experience discomfort/pain.

The results of the Pearson correlation coefficient method were obtained as there is highly significant correlation between Bag weight \& BMI $(\mathrm{r}=0.304)(\mathrm{p}=0.002)$ as shown in the table below.

Table 2:-Correlation of Bag weight \& BMI.

\begin{tabular}{|l|c|c|c|c|c|}
\hline \multicolumn{5}{|c|}{ Symmetric Measures } \\
\hline \multicolumn{2}{|l|}{ Correlation Method } & r value & $\begin{array}{c}\text { Asymp. Std. } \\
\text { Error }\end{array}$ & Approx. T & P value \\
\hline & Pearson's R & 0.304 & 0.101 & 3.154 & 0.002 \\
\hline & & & & & \\
\hline \multicolumn{7}{|l|}{} & & & & \\
\hline
\end{tabular}

The results of correlation between Bag weight \& Carrying duration daily obtained as $(\mathrm{r}=0.271)(\mathrm{p}=0.006)$ highly significant correlation as shown in the table below.

Table 3:-Correlation of Bag weight \& Carrying duration daily.

\begin{tabular}{|l|l|c|c|c|c|}
\hline \multicolumn{2}{|l|}{ Correlation method } & r value & $\begin{array}{c}\text { Asymp. Std. } \\
\text { Error }\end{array}$ & Approx & P value \\
\hline \multirow{2}{*}{ Pearson's R } & 0.271 & 0.092 & 2.789 & 0.006 \\
\hline & & & & & \\
\hline N of Valid Cases & & & & \\
\hline
\end{tabular}

The results of correlation between Bag weight \& Pain were obtained as highly significant correlation $(\mathrm{r}=0.271)(\mathrm{p}=0.006)$ as shown in the table below. 
Table 4: -Correlation of Bag weight \& Pain

\begin{tabular}{|c|c|c|c|c|c|}
\hline \multicolumn{5}{|c|}{ Symmetric Measures } \\
\hline Correlation method & Value & Asymp. Std. Error & Approx & P value \\
\hline & Pearson's R & 0.283 & .077 & 2.921 & 0.004 \\
\hline & & & & & \\
\hline \multicolumn{2}{|c|}{ N of Valid Cases } & 100 & & & \\
\hline
\end{tabular}

Whereas another correlation has also been done between pain and other variables \& the results obtained as there is highly significant correlation between Pain \& Bag weight $(\mathrm{r}=0.283)(\mathrm{p}=0.004)$ as shown in the above table, and between Pain \& the Carrying duration where $(\mathrm{r}=0.418)(\mathrm{p}=0.001)$ as shown in the table below.

Table 5:-Correlation of Pain \& Carrying duration

\begin{tabular}{|c|c|c|c|c|c|}
\hline \multicolumn{9}{|c|}{ Symmetric Measures } \\
\hline \multicolumn{2}{|l|}{} & Value & Asymp. Std. Error & Approx. & P value \\
\hline & Pearson's R & 0.418 & .068 & 4.559 & 0.001 \\
\hline & & & & & \\
\hline N of Valid Cases & 100 & & & & \\
\hline
\end{tabular}

But there has been none correlation found in between Pain, BMI, Distance travelled daily carrying bags on shoulders as $(\mathrm{p}>0.005)$.

The overall prevalence of Percentages of Pain(Questionnaire score categories) and BMI of all the samples are obtained through a cross tabulation method and the results shown are as follows, The students falling under $<18$ BMI category \& $<75$ score are 7.1\%, 75-105 score $64.3 \%, 105-130$ score $28.6 \%$. In 18-24 BMI category, $<75$ score $32.8 \%, 75-105$ score $44.8 \%, 105-130$ score $17.9 \%,>130$ score $4.5 \%$. In 25-29 BMI category, $<75$ score $13.3 \%, 75-$ 105 score $66.7 \%, 105-130$ score $20 \%$ and In $>30$ BMI category $75-105$ score $25 \%, 105-130$ score $50 \%,>130$ score $25 \%$ respectively. These results are represented through a table shown below.

Table 6:-Percentages of Questionnaire score \& BMI categories (Over all prevalence)

\begin{tabular}{|c|c|c|c|c|c|c|}
\hline \multicolumn{7}{|c|}{ BMI Categories \& Questionnaire Score Cross tabulation } \\
\hline & & \multicolumn{4}{|c|}{ Questionnaire Score } & \multirow[t]{2}{*}{ Total } \\
\hline & & $<75$ & $75-105$ & $105-130$ & $>130$ & \\
\hline \multirow[t]{3}{*}{$<18$} & Count & 1 & 9 & 4 & 0 & 14 \\
\hline & $\%$ within BMI Categories & $7.1 \%$ & $64.3 \%$ & $28.6 \%$ & $0.0 \%$ & $100.0 \%$ \\
\hline & \% within Questionnaire Score & $4.0 \%$ & $18.0 \%$ & $19.0 \%$ & $0.0 \%$ & $14.0 \%$ \\
\hline \multirow[t]{3}{*}{$18-24$} & Count & 22 & 30 & 12 & 3 & 67 \\
\hline & $\%$ within BMI Categories & $32.8 \%$ & $44.8 \%$ & $17.9 \%$ & $4.5 \%$ & $100.0 \%$ \\
\hline & \% within Questionnaire Score & $88.0 \%$ & $60.0 \%$ & $57.1 \%$ & $75.0 \%$ & $67.0 \%$ \\
\hline \multirow[t]{3}{*}{$25-29$} & Count & 2 & 10 & 3 & 0 & 15 \\
\hline & $\%$ within BMI Categories & $13.3 \%$ & $66.7 \%$ & $20.0 \%$ & $0.0 \%$ & $100.0 \%$ \\
\hline & \% within Questionnaire Score & $8.0 \%$ & $20.0 \%$ & $14.3 \%$ & $0.0 \%$ & $15.0 \%$ \\
\hline \multirow[t]{3}{*}{$>30$} & Count & 0 & 1 & 2 & 1 & 4 \\
\hline & $\%$ within BMI Categories & $0.0 \%$ & $25.0 \%$ & $50.0 \%$ & $25.0 \%$ & $100.0 \%$ \\
\hline & \% within Questionnaire Score & $0.0 \%$ & $2.0 \%$ & $9.5 \%$ & $25.0 \%$ & $4.0 \%$ \\
\hline \multirow[t]{3}{*}{ Total } & Count & 25 & 50 & 21 & 4 & 100 \\
\hline & $\%$ within BMI Categories & $25.0 \%$ & $50.0 \%$ & $21.0 \%$ & $4.0 \%$ & $100.0 \%$ \\
\hline & \% within Questionnaire Score & $100 \%$ & $100.0 \%$ & $100.0 \%$ & $100 \%$ & $100.0 \%$ \\
\hline
\end{tabular}

Whereas the overall prevalence Percentages of the Pain \& the Carrying duration are as follows, <6mnths carry \& falling under $<75$ category are about $42.4 \%, 75-105$ are 54.5\%, 105-130 are 3\%. 6-12mnths carry \& under $<75$ category are $21.9 \%, 75-105$ are $46.9 \%, 105-130$ are $31.3 \%$. $12-24$ mnths carry $\&$ under $<75$ category are $11.1 \%, 75-$ 105 are $55.6 \%, 105-130$ are $22.2 \%,>130$ score are $11.1 \%$ and $>24 \mathrm{mnths}$ carry $\&$ under $<75$ category are $12.5 \%, 75$ 105 are $25 \%, 105-130$ are $50 \%,>130$ are $12.5 \%$. 


\begin{tabular}{|c|c|c|c|c|c|c|c|}
\hline \multicolumn{8}{|c|}{ Table 7 : Carry duration \& Questionnaire Score Cross tabulation } \\
\hline & & & \multicolumn{4}{|c|}{ Questionnaire Score } & \multirow{3}{*}{$\begin{array}{r}\text { Total } \\
33\end{array}$} \\
\hline & & & $<75$ & $75-105$ & $\begin{array}{l}105- \\
130\end{array}$ & $>130$ & \\
\hline \multirow[t]{12}{*}{ Carry_duration } & \multirow[t]{3}{*}{$<6$ months } & Count & 14 & 18 & 1 & 0 & \\
\hline & & $\begin{array}{l}\% \text { within Carry } \\
\text { duration }\end{array}$ & $42.4 \%$ & $54.5 \%$ & $3.0 \%$ & $0.0 \%$ & $100.0 \%$ \\
\hline & & $\begin{array}{l}\% \text { within } \\
\text { Questionnaire Score }\end{array}$ & $56.0 \%$ & $36.0 \%$ & $4.8 \%$ & $0.0 \%$ & $33.0 \%$ \\
\hline & \multirow[t]{3}{*}{ 6-12months } & Count & 7 & 15 & 10 & 0 & 32 \\
\hline & & $\begin{array}{l}\text { \% within Carry } \\
\text { duration }\end{array}$ & $21.9 \%$ & $46.9 \%$ & $31.3 \%$ & $0.0 \%$ & $100.0 \%$ \\
\hline & & $\begin{array}{l}\% \text { within } \\
\text { Questionnaire Score }\end{array}$ & $28.0 \%$ & $30.0 \%$ & $47.6 \%$ & $0.0 \%$ & $32.0 \%$ \\
\hline & \multirow{3}{*}{$\begin{array}{l}12- \\
24 \text { months }\end{array}$} & Count & 3 & 15 & 6 & 3 & 27 \\
\hline & & $\begin{array}{l}\% \text { within Carry } \\
\text { duration }\end{array}$ & $11.1 \%$ & $55.6 \%$ & $22.2 \%$ & $11.1 \%$ & $100.0 \%$ \\
\hline & & $\begin{array}{l}\text { \% within } \\
\text { Questionnaire Score }\end{array}$ & $12.0 \%$ & $30.0 \%$ & $28.6 \%$ & $75.0 \%$ & $27.0 \%$ \\
\hline & \multirow[t]{3}{*}{$>24$ months } & Count & 1 & 2 & 4 & 1 & 8 \\
\hline & & $\begin{array}{l}\text { \% within Carry } \\
\text { duration }\end{array}$ & $12.5 \%$ & $25.0 \%$ & $50.0 \%$ & $12.5 \%$ & $100.0 \%$ \\
\hline & & $\begin{array}{l}\% \text { within } \\
\text { Questionnaire Score }\end{array}$ & $4.0 \%$ & $4.0 \%$ & $19.0 \%$ & $25 \%$ & $8.0 \%$ \\
\hline \multirow{3}{*}{\multicolumn{2}{|c|}{ Total }} & Count & 25 & 50 & 21 & 4 & 100 \\
\hline & & $\begin{array}{l}\% \text { within Carry } \\
\text { duration }\end{array}$ & $25.0 \%$ & $50.0 \%$ & $21.0 \%$ & $4.0 \%$ & $100.0 \%$ \\
\hline & & $\begin{array}{l}\% \text { within } \\
\text { Questionnaire Score }\end{array}$ & $100 \%$ & $100.0 \%$ & $100.0 \%$ & $100 \%$ & $100.0 \%$ \\
\hline
\end{tabular}

Percentages of the Pain \& the Time travelled daily are as follows, <10mins travel \& under category of < 75 are $18.2 \%, 75-105$ are $51.5 \%, 105-130$ are $27.3 \%,>130$ are $3 \% .10-20$ mins $\&<75$ are $37.5 \%, 75-105$ are $37.5 \%, 105-$ 130 are $18.8 \%,>130$ are $6.3 \% .20-30 \mathrm{mins} \&<75$ are $38.5 \%, 75-105$ are $46.2 \%, 105-130$ are $15.4 \% .30-40 \mathrm{mins} \&$ under $75-105$ are $100 \%$. 40-50mins \& $<75$ are $28.6 \%, 75-105$ are $57.1 \%, 105-130$ are $14.3 \%$. 50-60mins \& under $<75$ are $26.1 \%, 75-105$ are $52.2 \%, 105-130$ are $17.4 \%,>130$ are $4.3 \%$ and $>60$ mins $\&$ under $75-105$ are $57.1 \%, 105-$ 130 are $28.6 \%,>130$ are $14.3 \%$ respectively. The Frequency \& Percentages for the Mode of travel by the students daily has also been calculated and the results are shown as by Bus $45 \%$, by Walk $48 \%$ \& by Bike $7 \%$ respectively.)

Table 8:-Percentages of Questionnaire score \& Subjects Travelling time daily basis(Overall prevalence)

\begin{tabular}{|c|c|c|c|c|c|c|}
\hline \multicolumn{7}{|c|}{ Travelling Time \& Questionnaire Score Cross tabulation } \\
\hline & & \multicolumn{4}{|c|}{ Questionnaire Score } & \multirow[t]{2}{*}{ Total } \\
\hline & & $<75$ & $75-105$ & $\begin{array}{c}105- \\
130\end{array}$ & $>130$ & \\
\hline \multirow[t]{3}{*}{$<10$} & Count & 6 & 17 & 9 & 1 & 33 \\
\hline & $\%$ within Travelling Time & $18.2 \%$ & $51.5 \%$ & $27.3 \%$ & $3.0 \%$ & $100.0 \%$ \\
\hline & $\%$ within Questionnaire Score & $24.0 \%$ & $34.0 \%$ & $42.9 \%$ & $25.0 \%$ & $33.0 \%$ \\
\hline \multirow[t]{3}{*}{$10-20$} & Count & 6 & 6 & 3 & 1 & 16 \\
\hline & $\%$ within Travelling Time & $37.5 \%$ & $37.5 \%$ & $18.8 \%$ & $6.3 \%$ & $100.0 \%$ \\
\hline & \% within Questionnaire Score & $24.0 \%$ & $12.0 \%$ & $14.3 \%$ & $25.0 \%$ & $16.0 \%$ \\
\hline \multirow[t]{3}{*}{$20-30$} & Count & 5 & 6 & 2 & 0 & 13 \\
\hline & $\%$ within Travelling Time & $38.5 \%$ & $46.2 \%$ & $15.4 \%$ & $0.0 \%$ & $100.0 \%$ \\
\hline & \% within Questionnaire Score & $20.0 \%$ & $12.0 \%$ & $9.5 \%$ & $0.0 \%$ & $13.0 \%$ \\
\hline \multirow[t]{3}{*}{$30-40$} & Count & 0 & 1 & 0 & 0 & 1 \\
\hline & $\%$ within Travelling Time & $0.0 \%$ & $100.0 \%$ & $0.0 \%$ & $0.0 \%$ & $100.0 \%$ \\
\hline & \% within Questionnaire Score & $0.0 \%$ & $2.0 \%$ & $0.0 \%$ & $0.0 \%$ & $1.0 \%$ \\
\hline
\end{tabular}




\begin{tabular}{|c|l|r|r|r|r|r|}
\hline \multirow{3}{*}{$40-50$} & Count & 2 & 4 & 1 & 0 & 7 \\
\cline { 2 - 6 } & $\%$ within Travelling Time & $28.6 \%$ & $57.1 \%$ & $14.3 \%$ & $0.0 \%$ & $100.0 \%$ \\
\cline { 2 - 6 } & $\%$ within Questionnaire Score & $8.0 \%$ & $8.0 \%$ & $4.8 \%$ & $0.0 \%$ & $7.0 \%$ \\
\hline \multirow{3}{*}{$50-60$} & Count & 6 & 12 & 4 & 1 & 23 \\
\cline { 2 - 6 } & $\%$ within Travelling Time & $26.1 \%$ & $52.2 \%$ & $17.4 \%$ & $4.3 \%$ & $100.0 \%$ \\
\cline { 2 - 7 } & $\%$ within Questionnaire Score & $24.0 \%$ & $24.0 \%$ & $19.0 \%$ & $25.0 \%$ & $23.0 \%$ \\
\hline \multirow{3}{*}{$>60$} & Count & 0 & 4 & 2 & 1 & 7 \\
\cline { 2 - 7 } & $\%$ within Travelling Time & $0 \%$ & $57.1 \%$ & $28.6 \%$ & $14.3 \%$ & $100 \%$ \\
\cline { 2 - 7 } & \% within Questionnaire Score & $0 \%$ & $8 \%$ & $9.5 \%$ & $25 \%$ & $7 \%$ \\
\hline \multirow{3}{*}{ Total } & Count & 25 & 50 & 21 & 4 & 100 \\
\cline { 2 - 7 } & $\%$ within Travelling Time & $25 \%$ & $50 \%$ & $21.0 \%$ & $4 \%$ & $100 \%$ \\
\cline { 2 - 7 } & $\%$ within Questionnaire Score & $100 \%$ & $100 \%$ & $100 \%$ & $100 \%$ & $100 \%$ \\
\hline
\end{tabular}

\section{Discussion:-}

Determining the prevalence of musculoskeletal disorders is the first step in the prevention, diagnosis and treatment of the MSDs in adolescents and even adults. The purpose of this study was to determine the prevalence of musculoskeletal pain and its relation to the BMI of college girls those who are using heavy handbags. The results showed that the prevalence of Msk pain in students is $83.3 \%$. In this study, all students reported the most complaints in the Neck \& Shoulder followed by the Lower \& Upper back regions and least pain in the Arm \& Leg regions/zones.

In most of the studies, the cause of musculoskeletal pain in this age group is muscle weakness and pressure on joints due to inappropriate exercise \& also lack of daily activities. In a study by Bergman et al, the neck \& Lower back pain were the most prevalent msk pains in students in this age. Moreover in a study by Trevelyan \& colleagues, half of the students were at risk for Chronic Neck \& Low back pain. Additionally in a study by Smith et al, around 31\% of the students suffered from severe pain in Low back \& $36 \%$ had Neck pain.

According to this study a significant relationship between Bag weight, Pain, BMI \& Carrying duration was seen(p $<0.005$ ). In a study by Yue et al which has examined the association between demographic factors including Age, Height, BMI with the prevalence of musculoskeletal pain, a significant relationship between the above factors was observed. Likewise in another study by Azuan \& colleagues, a significant correlation of BMI, Weight of the bag, students Height with musculoskeletal pain was seen too.

\section{Conclusion:-}

Musculoskeletal discomfort/pain was reported among students of oxford educational institutions with overall prevalence of $83.3 \%$. This study discovered a high prevalence of Musculoskeletal pain with Bag weight \& Carrying duration, found to be predictors of discomforts. In most cases, this pain doesn't come from any particular illness/discomfort. It should be used more double strap bags than other type of single strap bags. Handbags have fewer consequences. Students are recommended not to use bags more than 20mins. In case they use handbags \& shoulder bags, they better use them alternatively on both shoulders. Accordingly more and comprehensive studies in this field are needed for the future. Future studies should explore more factors related to handbag use and investigate their long-term effect and association with MSDs or pain since musculoskeletal symptoms have multi factorial origin.

\section{Summary:-}

The Aim \& $1^{\text {st }}$ objective of this study was to find out the Prevalence of Musculoskeletal pain in college girls age ranging from 18-30yrs, using heavy Handbags. Out of 120 population, 100 samples had the pain in different regions of the body due to the loaded bags Data was collected using the data collection sheet \& the OMPQ. Overall prevalence was about $83.3 \%$. The mean weight of the bag was $3.2 \mathrm{~kg}(34 \%)$. The most severe pain was reported in the neck area followed by the shoulder \& low back areas. Moderate pain reported in the Upper back area. The least pain was reported in the Arm \& Leg areas.

Another objective was to find out the correlation of pain \& BMI, hence to find out that, Pearson correlation coefficient method was used. And the results obtained were, there is a relation between Bag weight, Pain, BMI \& 
Carrying duration as $\mathrm{P}$ values were less than 0.005 and hence proved as statistically highly significant correlation between the above mentioned variables.

\section{Refreferences:-}

1. Dr.Rajith Chauhan/The Pain Handbook/2016

2. Bag is killing u. (n.d.).

3. Carrying a Rucksack on shldr does it mattr. (n.d.).

4. Handbag Ergonomics. (n.d.).

5. Handbag syndrome. (n.d.).

6. National Centre for Chronic Disease Prevention and Health Promotion. May 15, 2015

7. Heavy purse syndrome. (n.d.).

8. Griegel- Morris et al, 1992 Griegel- Morris, P., Larson, K., Mueller- Kiaus, K., Oatis, C.A. (1992).Incidence of common postural abnormalities in the cervical, shoulder and thoracic regions and their association with pain in two age groups of healthy subjects. Physical therapy. 72(6): 424-431.

9. Ndetan HT, Rupert RL, Bae S, Singh KP. Epidemiology of musculoskeletal injuries among students entering a chiropractic college. J Manipulative Physiol Ther. 2009;32:134-9. doi: 10.1016/j.jmpt.2008.12.011.

10. Schwebel DC, Pitts DD, Stavrinos D. The influence of carrying a backpack on collegestudentpedestriansafety.AccidAnalPrev.2009;41:352-6. Doi:10.1016/j.aap.2009.01.002

11. Smith DR, Sato M, Miyajima T, Mizutani T, Yamagata Z. Musculoskeletal disorders self-reported by female nursing students in central Japan: a complete cross-sectional survey. Int J Nurs Stud. 2003;40:725-9

12. Grimmer, K. Dansie, B. Milanese, S. Pirunsan, U. and Trott, T. 2002. Adolescent standing postural response to backpack loads: a randomized controlled experimental study. BMC Musculoskeletal Disorders, 3:10. http://dx.doi.org/10.1186/1471-2474-310

13. American Occupational Therapy Association. National School Backpack Awareness Day 2008. [cited 2014 Feb 3]. Available from: http://news.health.com/2008/09/12/majority-college-students-report-backpackrelated-pain/

14. Martha, J.Sanders. 'Ergonomic and the management of musculoskeletal disorders', Elsevier health science. 2nded: p.556

15. American Occupational Therapy Association. Backpack Strategies for Parents andStudents2014.[cited2014Jan7].Availablefrom:http://www.promoteot.org/ai_backpacks trategies.html

16. Haselgrove, C., Straker, L., Smith, A., Sullivan, P. O., Perry, M., \& Sloan, N. (2008). Perceived school bag load , duration of carriage, and method of transport to school are associated with spinal pain in adolescents : an observational study, 54(2004), 193-200.

17. trunk muscle activity in diffrnt modes of carrying bags. (n.d.).

18. Brackley HM, Stevenson JM. Are children's backpack weight limits enough? A critical review of the relevant literature.Spine.2004;29(19):2184-90.[PMID 15454714].

19. APTA PT Bulletin Online. Archive page. Is your child's backpack making the grade?Availableat: http://www.apta.org/Media/Releases/Consumer/2009/4/14/. Accessed on June 29, 2012.

20. Influence of book bags on gait \& posture of youths. (n.d.).

21. Effects of backpacks on lumbosacral spine during walking. (n.d.).

22. Shumway-Cook A, Woollacott MH. Motor Control - Theory and Practical Applications. $2^{\text {nd }}$ Edition. Baltimore, MD: Lippincott, Williams and Wilkins; 2000

23. Bettany-Saltikov, J., \& Cole, L. (2012). The effect of frontpacks, shoulder bags and handheld bags on 3D back shape and posture in young university students: An ISIS2 study. Studies in Health Technology and Informatics, 176, 117-121. https://doi.org/10.3233/978-1-61499-067-3-117

24. Effect of same sided \& cross body load carriage on $3 \mathrm{~d}$ back shape in young adults . (n.d.).

25. Amani, F., Zakeri, A., Abbasi, V., Bahadoram, M., \& Davoodi, M. (2018). The prevalence of musculoskeletal pains among students The prevalence of musculoskeletal pains among students, (February). https://doi.org/10.15171/jpe.2018.06

26. Qureshi, Y., \& Shamus, E. (2012). Unilateral Shoulder Bags : Can They Be Worn in a Way to Reduce Postural Asymmetry?, 10(4), 1-9.

27. effect of simulated load carriage on shldr strap tension force. (n.d.).

28. Backpack usage \& self reported pain amng university students. (n.d.).

29. Hardie, R., Haskew, R., Harris, J., \& Hughes, G. (2015). The effects of bag style on muscle activity of the trapezius, erector spinae and latissimus dorsi during walking in female university students. Journal of Human Kinetics, 45(1), 39-47. https://doi.org/10.1515/hukin-2015-0005 
30. Ibrahim, A. A., Abdullahi, M., Specialist, W., Queen, S. S., Use, S., \& Discomforts, M. (2015). Influence of Schoolbag Use on Musculoskeletal Discomforts among University Students, (September).

31. The response of body when carrying a handbag. (n.d.).

32. Arghavani, V., Zamanian, Z., Ghanbary, A., \& Hassanzadeh, J. (2014). Investigation of the relationship between carrying school bags (handbags and backpacks) and the prevalence of musculoskeletal pains among 12-15 year old students in shiraz. Pakistan Journal of Biological Sciences. https://doi.org/10.3923/pjbs.2014.550.554

33. Panicker, R. K., \& Sandesh, T. S. (2014). Prevalence of Musculoskeletal Pain in School Going Adolescents Using School Bags : A Co-relational Research. https://doi.org/10.5455/ijtrr.00000039

34. Systematic review of predictive ability of orebro msk pain qstnre . (n.d.).

35. A Validation of Orebro msk pain qstnre . (n.d.).

\title{
Annexures:-
}

\section{ANNEXURE I}

The Oxford College Of Physiotherapy

Review Board on Ethics for Researeh

\begin{abstract}
Review Category : Exemption from Review Expedited Review Full Review
We hereby declare that the project titled, To Find Out Prevalence of Musculoskeletal Pain by Carrying Heavy Handbagn in College Girls in relation with their BMI carried out by Indu Priya.G, of Ist Year M.P.T has been brought forward for scrutiny to the board members.

Involvement of Special groups: No

Type of Study: Observational

AV Needs: No

After analyzing the objectives, subjects involved and the methodology of the study, the following conclusions were drawn. The study does not cause any mental or physical harm to the subjects involved and there are no risks involved in the study. The performance of the study procedure will not cause any injury to the subjects. The boand has evaluated and confirmed that the experimenter is trained and qualified in measuring outcome. The informed consent form ensures that the experimenter explains the procedure of the study to the subjects, their voluntary participations is confirmed and the identification of subjects is maintained confidential.
\end{abstract}

More over the finding of the study will benefit simitar subjects, the profession and the nociety. Hence the review board has no objections on the conduct of the study.

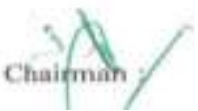

Ethical Consent Form

I, the undersigned, have fully understood that Mr/Miss/Mrs

is being a subject for undertaking the scientific study titled To Find Out Prevalence of Musculoskeletal Pain by Carrying Heavy Handbags in College Girls in Relation with BMI.

I have been made aware of the purpose for this study. I understand that I have to co-operate with the researcher for this study and a copy of the consent form has been given to me for my reference. 
Date:

Place:

Permission of the subject

Annexure Iii:-Consent Form

Title : To Find out Prevalence of Musculoskeletal Pain by Carrying Heavy Handbags in College Girls in Relation with their BMI

Investigator: Indu Priya. G(Post Graduate Student)

Subject's consent:

I Mr. / Miss/ Mrs. ........................... agree to participate in the study. I have understood the procedure of the study as explained to me by the investigator of the study. This study will help the health care professionals to know about the extent of difficulty faced by patients.

Purpose of the research : I have been informed by Indu Priya. G is going to do an Observational Study to find out the Prevalence of Musculoskeletal Pain by Carrying Heavy Handbags in College Girls in Relation with their BMI. This will help to formulate a better treatment plan for patients with all the musculoskeletal pains, mainly the shoulder and neck pains.

Procedure: I have been explained that this study is conducted without any interventions. The study involves 120 participants.

Risk and discomfort: I know there are no risks involved in participating in the study. If I feel any discomfort during intervention period Indu Priya. G will take appropriate care to safeguard the welfare and best interests of the subjects.

Benefits: This study will help to inform the subjects about the Effects of Heavy Handbags on Musculoskeletal system and Pain caused by it in relation with their BMI. The information so obtained shall provide insight into further research for establishment of data in context to Indian population.

The current study data shall provide guidance for physical therapists to plan a better patient specified treatment for multiple body pains/discomforts. This study will not provide any direct benefit to me.

Confidentiality: I understand that the medical information produced by this study will be confidential. Apart from the investigator no one will ever access to the data without my consent. If the data are used for the publication in the medical literature or for teaching purpose no name will be used.

Photography consent document:

I........................ have been explained by Indu Priya. G, that photograph are required in order to illustrate various aspect of the study for the thesis and other article, and at presentation and conference. These images may also be converted to electronic format for use in multimedia presentation and document accessible to other by computer for the purpose of sharing the result of the study and for promoting this research. By giving my consent I authorize her to use any of the photographs taken in printed format, in slides for presentation, and in electronic format. If the photograph is use the face will be taped to prevent identification.

Request for more information: I understand that I am encouraged to discuss any concerns regarding this study at any time. Indu Priya. G is available to answer my question to the best of her knowledge. A copy of this consent form will be given to me for my careful reading.

Refusal or withdrawal of participation:: I understand that my participation is voluntary and I may withdraw consent and discontinue participation any time without fear of prejudice. My decision whether or not to participate will not affect relationship with any agency, health care provider, etc. I also understand that she may terminate my participation in the study after she has explained the reason for doing so.

Non commercialization: The data collected will not be distributed for monetary benefit.

Investigator: Date:

I confirm that Indu Priya. G has explained me the purpose of this research, the study procedure and the possible risks and benefits associated that I may experience. I have read and understood this consent form to let myself participate as a subject in this research project and I am giving the consent wilfully.

Subject:

Date:

Annexure Iv:-Örebro Musculoskeletal Pain Questionnaire (ÖMPQ) (Linton and Boersma 2003)

$\begin{array}{ll}\text { 1. Name } & \text { Phone } \\ \text { 2.Date of Injury } & \text { Date of birth }\end{array}$

3. Male Female

4. Where do you have pain? Place a tick (3) for all appropriate sites. $\quad 2 x(\max 10)$ 
Neck Shoulder Arm $\quad$ Upper Back Lower Back Leg

5. How many days of work have you missed because of pain during the past 18 months? Tick (3) one.

0 days (1) 3-7 days (3) 8-14 days (4)

15-30 days (5) $\quad 1$ month (6) $\quad 2$ months (7) $\quad 3-6$ months (8)

6-12 months (9) over 1 year (10)

6 . How long have you had your current pain problem? Tick (3) one.

0-1 week (1) 1-2 weeks (2) 3-4 weeks (3) 4-5 weeks (4)

6-8 weeks (5) 9-11 weeks (6) 3-6 months (7) 6-9 months (8)

9-12 months (9) over 1 year (10)

7. Is your work heavy or monotonous? Circle the best alternative.

$\begin{array}{lllllllllll}0 & 1 & 2 & 3 & 4 & 5 & 6 & 7 & 8 & 9 & 10\end{array}$

Not at all Extremely

8. How would you rate the pain that you have had during the past week? Circle one.

$\begin{array}{lllllllllll}0 & 1 & 2 & 3 & 4 & 5 & 6 & 7 & 8 & 9 & 10\end{array}$

No pain Pain as bad as it could be

9. In the past three months, on average, how bad was your pain on a 0-10 scale? Circle one.

$\begin{array}{lllllllllll}0 & 1 & 2 & 3 & 4 & 5 & 6 & 7 & 8 & 9 & 10\end{array}$

No pain Pain as bad as it could be

10. How often would you say that you have experience pain episodes, on average, during the past three months?

Circle one.

$\begin{array}{lllllllllll}0 & 1 & 2 & 3 & 4 & 5 & 6 & 7 & 8 & 9 & 10\end{array}$

Never Always

11. Based on all things you do to cope, or deal with your pain, on an average day, how much are you able to decrease it? Circle the appropriate number. $\quad(10-\mathrm{X})$

$\begin{array}{lllllllllll}0 & 1 & 2 & 3 & 4 & 5 & 6 & 7 & 8 & 9 & 10\end{array}$

Can't decrease it at all Can decrease it completely

12. How tense or anxious have you felt in the past week? Circle one.

$\begin{array}{lllllllllll}0 & 1 & 2 & 3 & 4 & 5 & 6 & 7 & 8 & 9 & 10\end{array}$

Absolutely calm and relaxed As tense and anxious as I've ever felt

13. How much have you been bothered by feeling depressed in the past week? Circle one.

$\begin{array}{lllllllllll}0 & 1 & 2 & 3 & 4 & 5 & 6 & 7 & 8 & 9 & 10\end{array}$

Not at all Extremely

14. In your view, how large is the risk that your current pain may become persistent? Circle one.

$\begin{array}{lllllllllll}0 & 1 & 2 & 3 & 4 & 5 & 6 & 7 & 8 & 9 & 10\end{array}$

No risk Very large risk

15. In your estimation, what are the chances that you will be able to work in six months? Circle one. $(10-\mathrm{x})$

$\begin{array}{llllllllllll}0 & 1 & 2 & 3 & 4 & 5 & 6 & 7 & 8 & 9 & 10\end{array}$

No chance $\quad$ Very large chance

16. If you take into consideration your work routines, management, salary, promotion possibilities and work mates, how satisfied are you with your job? Circle one.

$\begin{array}{lllllllllll}0 & 1 & 2 & 3 & 4 & 5 & 6 & 7 & 8 & 9 & 10\end{array}$

Not satisfied at all Completely satisfied

17. Physical activity makes my pain worse.

$\begin{array}{llllllllllll}0 & 1 & 2 & 3 & 4 & 5 & 6 & 7 & 8 & 9 & 10\end{array}$

Completely disagree Completely agree

18. An increase in pain is an indication that I should stop what I'm doing until the pain decreases.

$\begin{array}{lllllllllll}0 & 1 & 2 & 3 & 4 & 5 & 6 & 7 & 8 & 9 & 10\end{array}$

Completely disagree Completely agree

19. I should not do my normal work with my present pain.

$\begin{array}{lllllllllll}0 & 1 & 2 & 3 & 4 & 5 & 6 & 7 & 8 & 9 & 10\end{array}$

Completely disagree Completely agree

20.I can do light work for an hour $(10-\mathrm{x})$

$(10-x)$ 
$\begin{array}{lllllllllll}0 & 1 & 2 & 3 & 4 & 5 & 6 & 7 & 8 & 9 & 10\end{array}$

Can't do it because of pain problem

21 . I can walk for an hour.

$\begin{array}{lllllllllll}0 & 1 & 2 & 3 & 4 & 5 & 6 & 7 & 8 & 9 & 10\end{array}$

Can't do it because of pain problem

22. I can do ordinary household chores.

$\begin{array}{lllllllllll}0 & 1 & 2 & 3 & 4 & 5 & 6 & 7 & 8 & 9 & 10\end{array}$

Can't do it because of pain problem

23. I can do the weekly shopping.

$\begin{array}{lllllllllll}0 & 1 & 2 & 3 & 4 & 5 & 6 & 7 & 8 & 9 & 10\end{array}$

Can't do it because of pain problem

24. I can sleep at night.

$\begin{array}{lllllllllll}0 & 1 & 2 & 3 & 4 & 5 & 6 & 7 & 8 & 9 & 10\end{array}$

Can't do it because of pain problem

Annexure V:-Proforma

NAME :

AGE :

GENDER :

BAG WEIGHT :

TYPE OF CARRY : UNILATERAL

TRAVELLING DISTANCE DAILY :

CARRYING DURATION :

BODY WEIGHT :

BODY HEIGHT :

BMI :
Can do it without pain being a problem

$$
(10-\mathrm{x})
$$

Can do it without pain being a problem

$$
(10-\mathrm{x})
$$

Can do it without pain being a problem

$$
(10-\mathrm{x})
$$

Can do it without pain being a problem

$$
(10-\mathrm{x})
$$

\begin{tabular}{|c|c|c|c|c|c|c|c|c|}
\hline Age & $\begin{array}{l}\text { Bag weight } \\
(\mathrm{Kg})\end{array}$ & $\begin{array}{l}\text { Carry } \\
\text { duration } \\
\text { (Mnths) }\end{array}$ & $\begin{array}{l}\text { Distance } \\
\text { Travelled } \\
\text { (Mins) }\end{array}$ & $\begin{array}{l}\text { Mode } \\
\text { of } \\
\text { travel }\end{array}$ & $\begin{array}{l}\text { Body } \\
\text { Weight } \\
(\mathrm{kg})\end{array}$ & $\begin{array}{l}\text { Body } \\
\text { Height } \\
(\mathrm{cm})\end{array}$ & BMI & Questionnaire score \\
\hline 21 & 1.98 & 12 & 5 & Walking & 57.5 & 162 & 21.9 & 83 \\
\hline 21 & 4.27 & 48 & 15 & Bike & 57.2 & 161 & 22.1 & 69 \\
\hline 26 & 3.65 & 9 & 60 & Bus & 73.9 & 163 & 27.8 & 96 \\
\hline 26 & 3.64 & 24 & 30 & Bus & 54.2 & 160 & 21.2 & 53 \\
\hline 25 & 3.68 & 24 & 10 & Walking & 45.6 & 156 & 18.7 & 96 \\
\hline 21 & 4.15 & 6 & 45 & Bike & 79.8 & 171 & 27.3 & 92 \\
\hline 21 & 2.23 & 9 & 15 & Walking & 60.6 & 156 & 24.9 & 66 \\
\hline 21 & 3.43 & 1 & 5 & Walking & 51.3 & 164 & 19.1 & 92 \\
\hline 24 & 4.53 & 24 & 15 & Walking & 59.7 & 153 & 25.5 & 96 \\
\hline 25 & 2.5 & 24 & 30 & Bus & 59.1 & 166 & 21.4 & 53 \\
\hline 25 & 5 & 12 & 10 & Walking & 54.7 & 162 & 20.8 & 73 \\
\hline 26 & 4.9 & 24 & 60 & Bus & 57 & 150 & 25.3 & 115 \\
\hline 20 & 2.7 & 12 & 45 & Bus & 45.2 & 162 & 17.2 & 88 \\
\hline
\end{tabular}

Can do it without pain being a problem

\section{MUSCULOSKELETAL PAIN DUE TO BAG : PRESENT $\quad$ ABSENT}

ANNEXURE VI :-Master chart 


\begin{tabular}{|c|c|c|c|c|c|c|c|c|}
\hline 18 & 2.55 & 12 & 15 & Walking & 44.3 & 164 & 16.5 & 109 \\
\hline 19 & 3.64 & 24 & 120 & Bus & 76.5 & 151 & 33.6 & 117 \\
\hline 18 & 2.05 & 12 & 45 & Bus & 59.8 & 172 & 20.2 & 71 \\
\hline 18 & 3.58 & 12 & 60 & Bus & 51.6 & 158 & 20.7 & 115 \\
\hline 20 & 3.19 & 6 & 20 & Walking & 56.3 & 156 & 23.1 & 65 \\
\hline 18 & 4.63 & 12 & 60 & Bus & 56.3 & 156 & 23.1 & 50 \\
\hline 20 & 2.38 & 12 & 45 & Bus & 51.7 & 166 & 18.8 & 43 \\
\hline 21 & 2.4 & 12 & 60 & Bus & 45.4 & 150 & 20.2 & 65 \\
\hline 19 & 1.92 & 12 & 20 & Walking & 44.8 & 162 & 16.8 & 79 \\
\hline 18 & 3.17 & 12 & 120 & Bus & 54 & 162 & 20.6 & 102 \\
\hline 18 & 3.3 & 24 & 5 & Walking & 52.4 & 164 & 19.5 & 92 \\
\hline 18 & 3.44 & 12 & 60 & Bus & 49.3 & 164 & 18.3 & 82 \\
\hline 18 & 1.33 & 1 & 120 & Walking & 50.4 & 156 & 20.7 & 96 \\
\hline 18 & 1.32 & 1 & 30 & Bus & 53.9 & 153 & 23 & 54 \\
\hline 18 & 2.22 & 1 & 10 & Bike & 43.4 & 149 & 19.5 & 85 \\
\hline 19 & 3.6 & 1 & 5 & Walking & 48.2 & 143.5 & 23.4 & 19 \\
\hline 18 & 2 & 1 & 60 & Bus & 50.9 & 156.5 & 20.8 & 73 \\
\hline 18 & 3.33 & 1 & 60 & Bus & 54.8 & 159 & 21.9 & 84 \\
\hline 19 & 1.86 & 1 & 60 & Bus & 47.1 & 159 & 18.6 & 84 \\
\hline 18 & 2.62 & 1 & 45 & Bus & 47.5 & 164 & 17.7 & 80 \\
\hline 18 & 3 & 1 & 15 & Walking & 44.6 & 164 & 16.6 & 85 \\
\hline 18 & 2.72 & 1 & 30 & Bus & 42.5 & 163 & 16 & 39 \\
\hline 20 & 3.83 & 1 & 30 & Bus & 45.2 & 140.5 & 22.9 & 82 \\
\hline 19 & 3.95 & 1 & 30 & Bus & 76.7 & 164 & 28.5 & 44 \\
\hline 18 & 2.32 & 1 & 15 & Walking & 47.4 & 153 & 20.2 & 59 \\
\hline 18 & 2.8 & 1 & 60 & Bus & 56.6 & 155 & 23.6 & 92 \\
\hline 18 & 4.1 & 1 & 60 & Bus & 46.6 & 151 & 20.4 & 77 \\
\hline 18 & 2.53 & 1 & 60 & Bus & 49.5 & 146 & 23.2 & 38 \\
\hline 18 & 3.74 & 1 & 60 & Bus & 59.6 & 144.5 & 28.5 & 78 \\
\hline 21 & 5.02 & 1 & 5 & Walking & 58.6 & 150 & 26 & 80 \\
\hline 18 & 5.51 & 18 & 5 & Walking & 45.3 & 162.5 & 17.2 & 84 \\
\hline 22 & 2.02 & 24 & 60 & Bus & 34.9 & 144 & 16.8 & 87 \\
\hline 20 & 3.39 & 18 & 60 & Bus & 52.9 & 154 & 22.3 & 121 \\
\hline 19 & 3.81 & 2 & 20 & Bus & 54.6 & 153 & 23.3 & 64 \\
\hline 19 & 3 & 12 & 15 & Bike & 60.9 & 155 & 25.3 & 108 \\
\hline 18 & 2.63 & 12 & 30 & Walking & 45.6 & 158 & 18.3 & 117 \\
\hline 19 & 4.9 & 14 & 120 & Bus & 48.3 & 165.5 & 17.6 & 95 \\
\hline 20 & 3.66 & 18 & 40 & Bus & 49.1 & 151 & 21.5 & 94 \\
\hline 20 & 3.18 & 12 & 60 & Bus & 51.6 & 150.5 & 22.8 & 92 \\
\hline 19 & 3.29 & 18 & 60 & Bus & 56.6 & 167 & 20.3 & 136 \\
\hline 20 & 3.99 & 18 & 180 & Bus & 44.2 & 154 & 18.6 & 147 \\
\hline 19 & 2.37 & 18 & 30 & Bike & 48.2 & 157 & 19.6 & 96 \\
\hline 20 & 3.59 & 12 & 60 & Bus & 50.7 & 158.5 & 20.2 & 74 \\
\hline 19 & 2.69 & 1 & 60 & Bus & 53.9 & 153 & 23 & 89 \\
\hline 19 & 3.88 & 12 & 120 & Bus & 50.6 & 163 & 19 & 106 \\
\hline 20 & 3 & 24 & 20 & Walking & 70 & 164 & 26 & 98 \\
\hline 22 & 4.41 & 1 & 60 & Bus & 59.2 & 157 & 24 & 78 \\
\hline 22 & 6.1 & 12 & 30 & Walking & 85.7 & 163 & 32.3 & 105 \\
\hline 18 & 4.54 & 24 & 10 & Walking & 59 & 152 & 26.5 & 92 \\
\hline 23 & 4.53 & 12 & 10 & Walking & 37 & 161 & 14.3 & 125 \\
\hline 23 & 4.3 & 60 & 30 & Bus & 60 & 169 & 22 & 125 \\
\hline 21 & 2.26 & 36 & 10 & Walking & 43 & 164 & 16 & 87 \\
\hline 25 & 2.98 & 48 & 5 & Walking & 50 & 152 & 21.6 & 111 \\
\hline
\end{tabular}




\begin{tabular}{|c|c|c|c|c|c|c|c|c|}
\hline 23 & 5.28 & 60 & 15 & Walking & 70 & 152.4 & 30.1 & 134 \\
\hline 22 & 5.15 & 72 & 45 & Bus & 63 & 155 & 26.2 & 107 \\
\hline 20 & 1.71 & 4 & 5 & Walking & 40 & 154 & 16.9 & 109 \\
\hline 20 & 4 & 6 & 5 & Walking & 52 & 154 & 21.9 & 70 \\
\hline 18 & 3.97 & 6 & 5 & Walking & 55 & 160 & 21.5 & 99 \\
\hline 22 & 3.5 & 36 & 5 & Walking & 72 & 154 & 30.4 & 115 \\
\hline 19 & 4.66 & 12 & 5 & Walking & 55 & 168 & 19.5 & 113 \\
\hline 21 & 4.51 & 3 & 10 & Walking & 72 & 160 & 28.1 & 103 \\
\hline 20 & 3.6 & 12 & 10 & Walking & 59 & 168 & 20.9 & 113 \\
\hline 19 & 3 & 1 & 15 & Bike & 54 & 152 & 23.4 & 58 \\
\hline 19 & 2 & 1 & 5 & Walking & 46 & 152 & 19.9 & 52 \\
\hline 21 & 1.72 & 3 & 45 & Bus & 44 & 152 & 19 & 102 \\
\hline 21 & 3.77 & 24 & 180 & Bus & 65 & 162 & 24.8 & 81 \\
\hline 22 & 3.5 & 1 & 60 & Bus & 46.3 & 157 & 18.8 & 48 \\
\hline 22 & 1 & 2 & 5 & Walking & 58.9 & 163 & 22.2 & 69 \\
\hline 23 & 4.54 & 12 & 10 & Walking & 56.5 & 156 & 23.2 & 125 \\
\hline 23 & 3.73 & 7 & 10 & Walking & 44.8 & 159 & 17.7 & 92 \\
\hline 23 & 2.89 & 9 & 15 & Walking & 59.5 & 162 & 22.7 & 92 \\
\hline 23 & 2 & 7 & 10 & Walking & 55 & 164 & 20 & 87 \\
\hline 23 & 2.51 & 24 & 5 & Walking & 50 & 164 & 19 & 117 \\
\hline 22 & 1.54 & 36 & 10 & walking & 70 & 164 & 26 & 96 \\
\hline 23 & 1.84 & 7 & 30 & Walking & 50 & 164 & 19 & 80 \\
\hline 23 & 1.49 & 19 & 5 & Walking & 54 & 164 & 20 & 70 \\
\hline 23 & 3 & 24 & 10 & Walking & 45 & 152 & 19 & 164 \\
\hline 26 & 5 & 24 & 20 & Walking & 54 & 158 & 22 & 128 \\
\hline 27 & 4 & 24 & 60 & Bike & 65 & 164 & 24 & 82 \\
\hline 27 & 5 & 24 & 60 & Bus & 42 & 161 & 16 & 112 \\
\hline 26 & 2.9 & 24 & 30 & Bus & 65 & 163 & 24 & $\overline{94}$ \\
\hline 27 & 5 & 24 & 20 & Walking & 53 & 161 & 20 & 105 \\
\hline 25 & 1.5 & 24 & 30 & Bus & 65 & 173 & 22 & 86 \\
\hline 22 & 1.56 & 12 & 10 & Walking & 60 & 163 & 24 & 84 \\
\hline 22 & 1.48 & 12 & 10 & Walking & 55 & 164 & 20 & 80 \\
\hline 20 & 4.5 & 12 & 10 & Walking & 62 & 167 & 22 & 108 \\
\hline 19 & 4 & 12 & 10 & Walking & 55 & 158 & 22 & 105 \\
\hline
\end{tabular}

